\title{
Study on Relationship Between Age and Coffee Preference: Application to Specialty Coffee Association Brewing Control Chart
}

\author{
Joy Xue ${ }^{1 *}$ \\ ${ }^{1)}$ Concordia International School Shanghai, 345 Huangyang Road Pudong, Shanghai China 201206 \\ ${ }^{*}$ Corresponding author: joy.yula.xue @ gmail.com \\ Received: 14 March 2019 / Accepted: 21 June 2019
}

\begin{abstract}
The Specialty Coffee Association Brewing Control chart has been used for the past 50 years, and is intended to assist the coffee brewer by stating the brew ratio and TDS (total dissolved solids) value needed to brew an "ideal" cup of coffee. Since coffee is a common and popular beverage that is consumed among populations ranging from children to elders, the objective of this study was to find out whether taste preferences in coffee vary based on age and whether these preferences match the current brewing control chart standard. Data collected in this study was based on a taste test with 32 total participants selected randomly. Of these participants, 10 fell into the 10-19 years old age range, 5 in the 20-29 range, 4 in the 30-39 range, 7 in the 40-49 range, and 6 in the 50-59 range. Based on the data from these respondents, no obvious trend between age range and coffee preference was observed; but, this is subject to change with larger sample sizes. Overall taste preferences, however, do generally fit the current standard ideal range on the coffee brewing control chart.
\end{abstract}

Keywords: Total dissolved solids, coffee preference, brewing control chart, age, sensory, flavour

\section{INTRODUCTION}

As coffee gains popularity, it has become a beverage enjoyed by people of all ages. In order to tailor the coffee brewing control chart to each age group taste preferences, this study was conducted to identify and understand where each group's "ideal" region is located. In addition to this, the other goal of this study was to find out if taste preferences have altered over the years by locating and comparing current preferences to the Specialty Coffee Association (SCA) brewing control chart (Frost, 2018).

Coffee preference refers to an individual personal level of liking for a type of coffee. It is hypothesized that age is linked to a change in taste preference due to a biological evolution in the gustatory system (Fleming, 2013). The SCA brewing control chart was created in the 1957 by MIT chemistry professor E.E. Lockhart (Suarez et al., 2013). According to the chart, the ideal or "perfection" range for coffee that Americans enjoy lies between a brew strength of $1.1 \%$ to $1.3 \%$ and a golden brew ratio of 17.42 units of water to one unit of coffee.

There have been several attempts to approach the coffee brewing control chart in new ways and adjust it to fit modern conditions. For example, the UC Davis Coffee Center is currently doing research on the analysis of sensory attributes in respect to the coffee brewing control chart (Frost, 2018). Another research paper regarding the addition of factors such as brew time 
and grind size to the chart and their relations to brew strength (Anonim, 2018). Previous studies conducted by the Specialty Coffee Association of Europe have also focused on understanding coffee extraction preferences as part of the SCAE Gold Cup research, aiming to set the brewing standard for filtered coffee in Europe. One of such studies is the experiment on European extraction preferences where taste tests were conducted in four different countries across the continent (SCAE, 2013).

There were two main intentions for this research. The first was to find out whether there is a relationship between age and coffee preference, which, if identified, could be useful for coffee businesses to tailor customers' experiences. The second was to see if current taste preferences align with the ones set by the coffee brewing control chart created around 60 years ago, because if preferences have changed over the years, the brewing control chart can be updated to fit the data.

\section{MATERIALS AND METHODS}

For this study, taste tests were conducted in order to collect data regarding coffee preference. The coffee beans used for this taste test were medium roast Hani Fuyan coffee beans from Yunnan, China. These beans were roasted three weeks before the taste tests.

The coffee was brewed to three different brew strengths for the taste test: ideal, strong sour, and weak bitter, and labeled A, B, and $\mathrm{C}$ respectively. Brew A had a brew ratio of 17 resulting from $25 \mathrm{~g}$ of coffee grounds and $425 \mathrm{~mL}$ of water. Brew B had a brew ratio of 12 with $35 \mathrm{~g}$ of coffee grounds and $420 \mathrm{~mL}$ of water. Lastly, Brew $\mathrm{C}$ had a brew ratio of 25 from $15 \mathrm{~g}$ of coffee grounds and $375 \mathrm{~mL}$ of water. For each brew, the coffee grind size was kept at one. The water and coffee grounds were all measured using a balance and brewed with a Clever drip brewer and paper filter. After heating the water in a kettle to $97^{\circ} \mathrm{C}$, the filter was first wet with $10 \mathrm{~mL}$ of water and emptied. Then, the coffee grounds were poured in, and once the water reached $97^{\circ} \mathrm{C}$ again, the water was poured into the grounds in order to let it extract and the lid was placed on top (Ristenpart \& Kuhl, 2017). Each brew was extracted for different amounts of time to get the desired total dissolved solids (TDS) values (Figure 1). Brew A had an extraction time of eight minutes, Brew B had seven minutes, and Brew $\mathrm{C}$ had five minutes. After each minute, the coffee was stirred, and once it reached its extraction time, the coffee was released into a food grade beaker. Each brew was then measured using refractometers to identify the TDS value, which reflects brew strength based on extraction. The TDS for Brew A was around $1.23 \%$, Brew B was around $2.04 \%$, and Brew $\mathrm{C}$ was around $1.02 \%$.

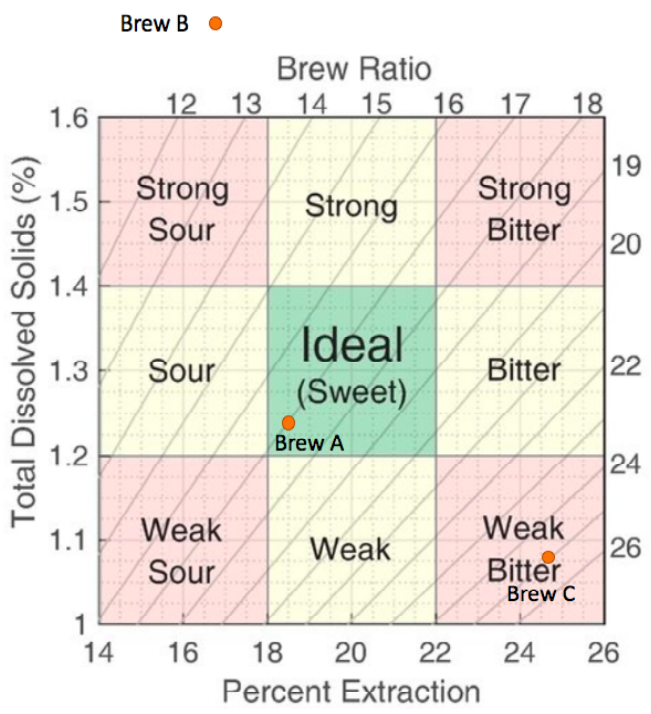

Figure 1. The location of the three brews on the coffee brewing control chart, based on total dissolved solids (TDS) and brew ratio

The actual taste test portion of the procedure involved the participation of respondents and a rating form for the coffee. The respondents were chosen randomly, but all have 
tasted coffee before; in fact, most of them enjoy coffee on a regular basis. For each individual participating in the study, they were given a sheet to fill out with questions regarding age range, gender, and how often they drink coffee. The coffee was then poured into small tasting cups and given one by one to the individual to try. For each brew, the respondent checked a box representing their personal preference by scoring the coffee on a scale from "dislike extremely" to "like extremely" (Figure 3). This rating scale was the one used in the SCAE European extraction preferences study (SCAE, 2013).
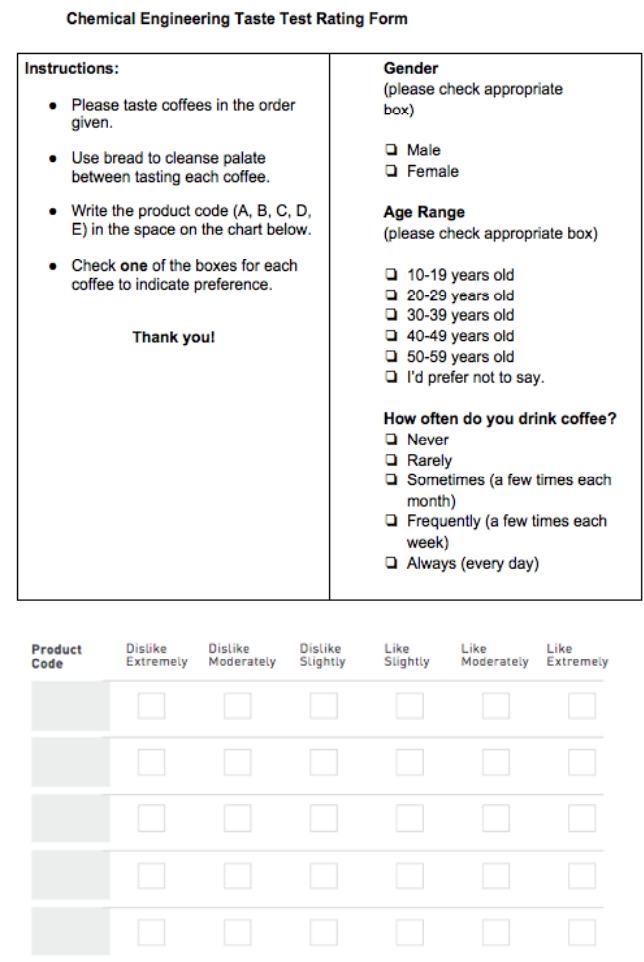

Figure 2. The rating form filled out by the respondents

\section{RESULTS AND DISCUSSION}

From the data collected, various graphs were created to identify any trends and apply them to the brewing control chart (Frost, 2018). To analyze the data, which follows a Likert scale, the responses from each taste test participant were first used to make a frequency graph. When looking at coffee preference for each age group separately, some trends are evident. The first age group consisted of individuals from 10 to 19 years old. There were 10 people in this age range who participated in the taste test.

After organizing the data into a table to see the various responses from each person in the first age group, the numbers were used to make the frequency graphs (Figure 3). In order to see the trend more clearly, a separate graph was made for each brew. In the graph for Brew A, the preference for the age group leaned toward like rather than dislike, with the most responses for "like slightly," making it the most preferred out of the three brews. Brew B, on the other hand, was the least preferable with $70 \%$ of the respondents disliking the coffee. For Brew B, the most responses were given for "dislike slightly." The opinions toward the third brew, Brew C, were rather neutral compared to the other two brews. Like Brew A, this brew was also more preferred than disliked; however, $50 \%$ of the respondents chose "like slightly" and $20 \%$ chose "dislike slightly" which, as reflected by the graph, shows preferences that were less extreme.

The next age group consisted of five individuals ranging from 20 to 29 years old. The frequency graphs for this age group showed similar results to the first age group. Brew A had three respondents who chose "like slightly" and two who chose "dislike slightly," so the preference here was rather balanced but generally leaning more toward a preferable brew. $80 \%$ of the respondents in this age group disliked the coffee from Brew B, making it the least preferable out of the three brews, just like in the first age group. Brew $\mathrm{C}$ had generally neutral results again, but was more preferred since $40 \%$ of the respondents chose "like moderately." 


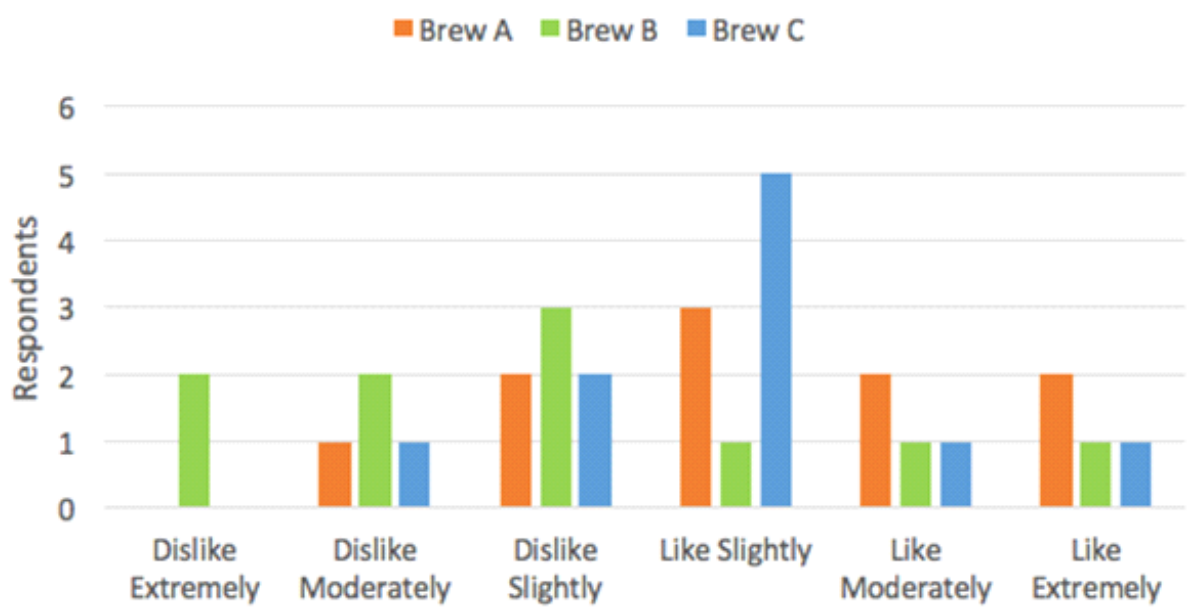

Figure 3. The frequency graph showing preferences for age range 10 to 19 years old

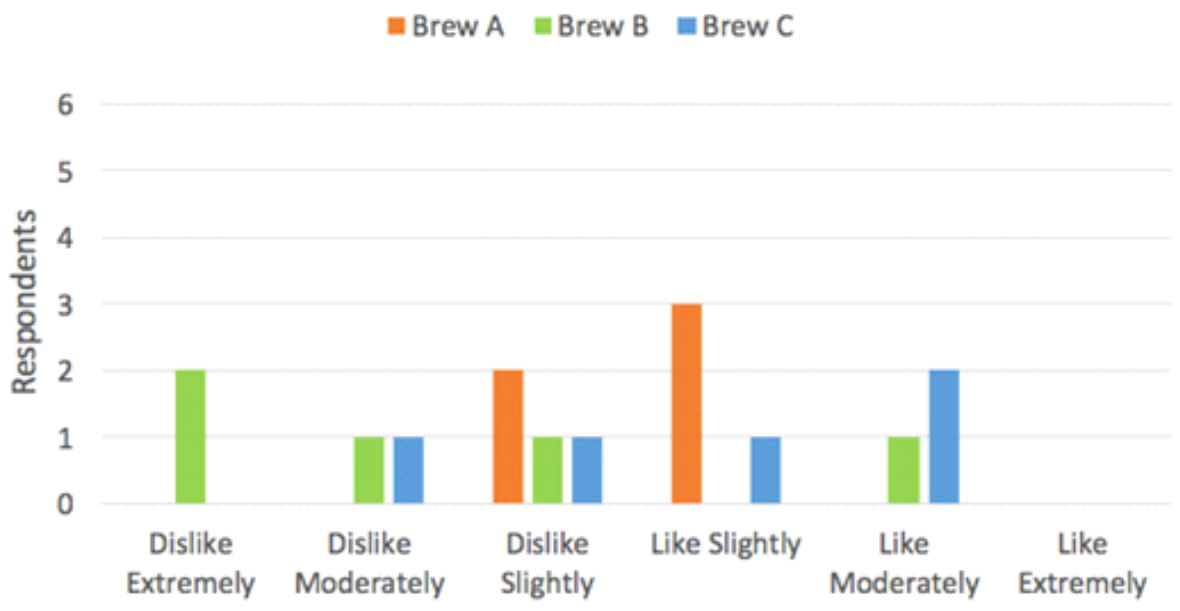

Figure 4. The frequency graph showing preferences for age range 20 to 29 years old

The third group had four individuals in the 30 to 39 -year-old range. The preferences for the third age group were slightly different from the first two. Brew A was still the most preferable brew for this age group with all of the respondents choosing either "like slightly" or "like moderately." However, Brew B was not the least preferred brew for this age group. The frequency graph displayed a rather balanced result with $50 \%$ disliking the coffee and 50\% liking it. Instead, Brew $\mathrm{C}$ became the least preferred brew out of the three for this age group even though its results were also generally neutral. Like brew B, 50\% liked Brew C and $50 \%$ disliked it; but, there was a respondent who chose "dislike extremely" for this brew. 


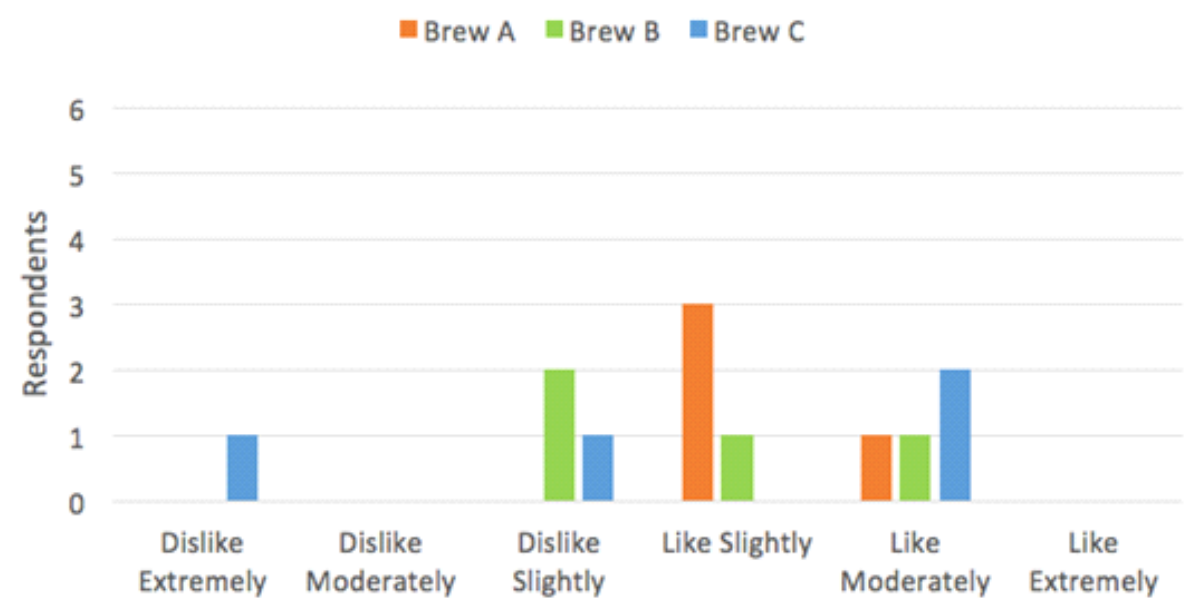

Figure 5. The frequency graph showing preferences for age range 30 to 39 years old

The next age group consisted of individuals ranging from 40 to 49 . There were seven respondents who fit into this age group. The results for all three brews in this age group were distributed and balanced. Unlike the other age groups, Brew A was not the most preferred out of the three brews. Three of the respondents liked Brew A while four respondents disliked the brew. Among those four respondents, two of them chose "dislike moderately" and one chose "dislike extremely" which pulled the general preference toward dislike. Similar to Brew A, there were three respondents who liked Brew B and four respondents who disliked the brew. However, out of the dislikes, three of them were for "dislike moderately" thus also making the brew generally less preferable. Out of the three brews, Brew $\mathrm{C}$ was the most preferred for this age group. Although the data was distributed rather equally, there were two respondents who chose "like moderately," making the preference lean in that direction.

The last group had six respondents who fell in the age range of 50 to 59 years old.
For this age group, Brew A was the most preferred brew out of the three once again. There was one outlier who disliked the coffee, but all five of the other respondents liked the brew. Out of those five respondents, four chose "like moderately." The results for Brew B were spread out and distributed equally. Based on this data, as displayed in the graph, there was no clear preference for Brew B among this age group. Finally, results for Brew $\mathrm{C}$ were also neutral with $50 \%$ of the respondents liking the coffee and 50\% disliking the brew. However, while five of the choices were either "dislike slightly" or "like slightly" there was one response for "like moderately," resulting in a slight preference for Brew C.

Using the data from each separate graph, general frequency graphs were also made according to each brew in order to determine whether current coffee preferences match the standard preferences identified by the SCA brewing control chart (Frost, 2018). On the brewing control chart, a brew that is in the "ideal" range has a TDS of $1.2 \%$ to $1.4 \%$ and a brew ratio of around 16 to 19 . 


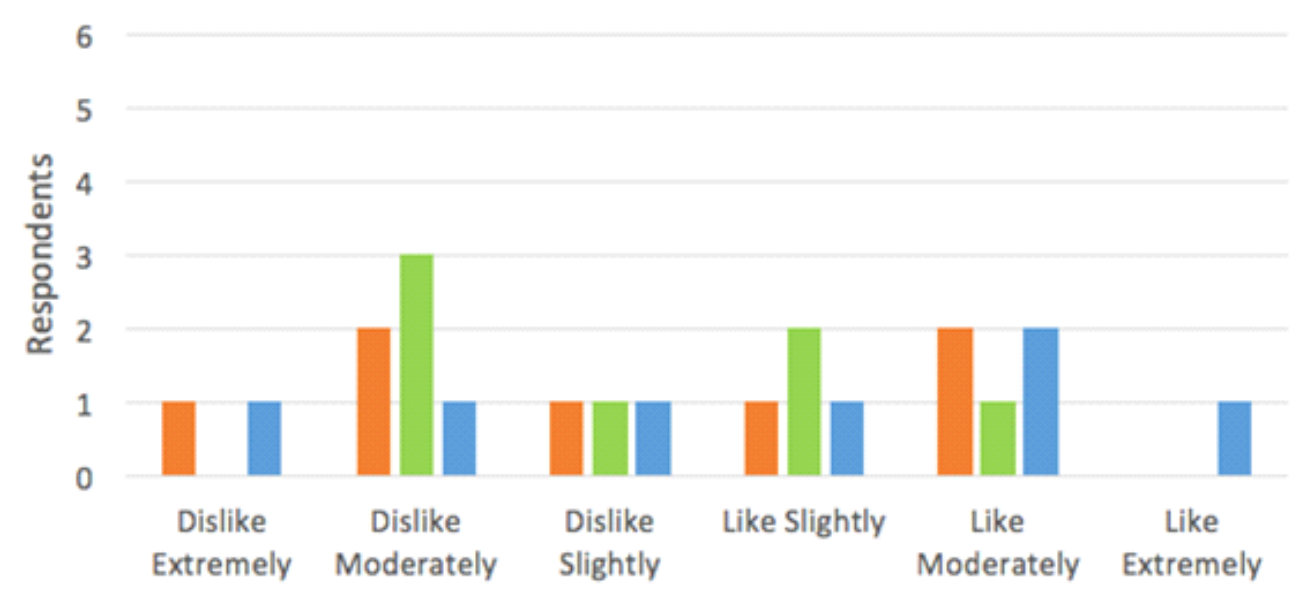

Figure 6. The frequency graph showing preferences for age range 40 to 49 years old

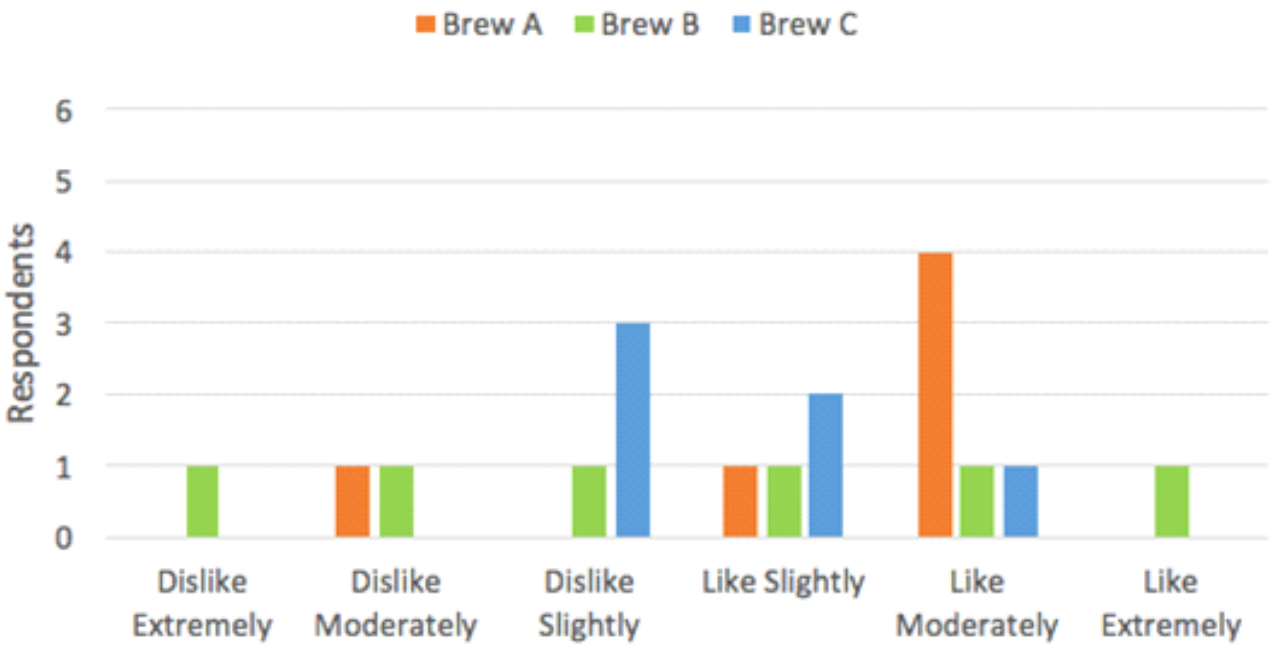

Figure 7. The frequency graph showing preferences for age range 50 to 59 years old

Brew A had a TDS of around $1.23 \%$ and a brew ratio of 17 ; thus, it lands in the "ideal" region. The trend in the combined frequency graph for Brew A shows an increase in number of respondents as the preference moves away from "dislike extremely" and toward "like extremely." Based on this data, it can be inferred that Brew A is generally liked by the current population, regardless of age, which matches its location on the brewing chart. On the other hand, Brew B had a TDS of around $2.04 \%$ and a brew ratio of 12 , so it was considered "strong" and located far from the "ideal" region, meaning a coffee brewed with these values would not be enjoyed by most people. This is supported by Brew B's combined frequency graph since most responses were either "dislike moderately" or "dislike slightly." Furthermore, the trend generally decreases as it moves toward "like extremely." Lastly, Brew $\mathrm{C}$ had a TDS of around $1.02 \%$ and a brew 
ratio of 25 , making it a brew in the "weak bitter" region of the brewing control chart. Therefore, it is not considered an "ideal" coffee but is still located on the chart, so it should not be disliked by the majority of people either. In the combined frequency graph for Brew $\mathrm{C}$, it is evident that the general preference leans toward the middle, with most of the respondents choosing "dislike slightly" or "like slightly." This shows a rather neutral preference, which fits its location on the brewing control chart.
To see a clear application of the data to the SCA brewing control chart (Frost, 2018), a bubble chart was used. The size of each circle on the bubble chart represents the number of respondents who chose either "like slightly," "like moderately," or "like extremely" for each brew. The sizes are proportional, so the larger the circle, the more people who liked the coffee. Each color represents a certain age group. This was added with the purpose of assisting in identifying any trends between age and coffee preference.

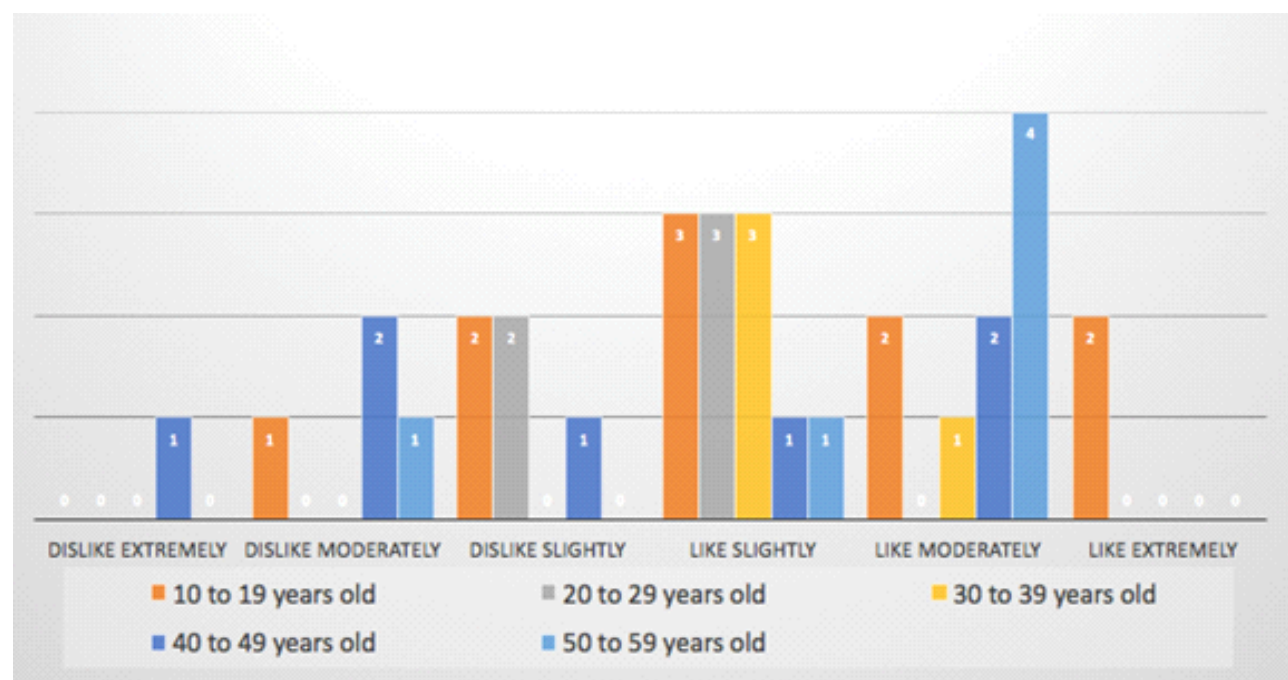

Figure 8. Combined frequency graph for brew A

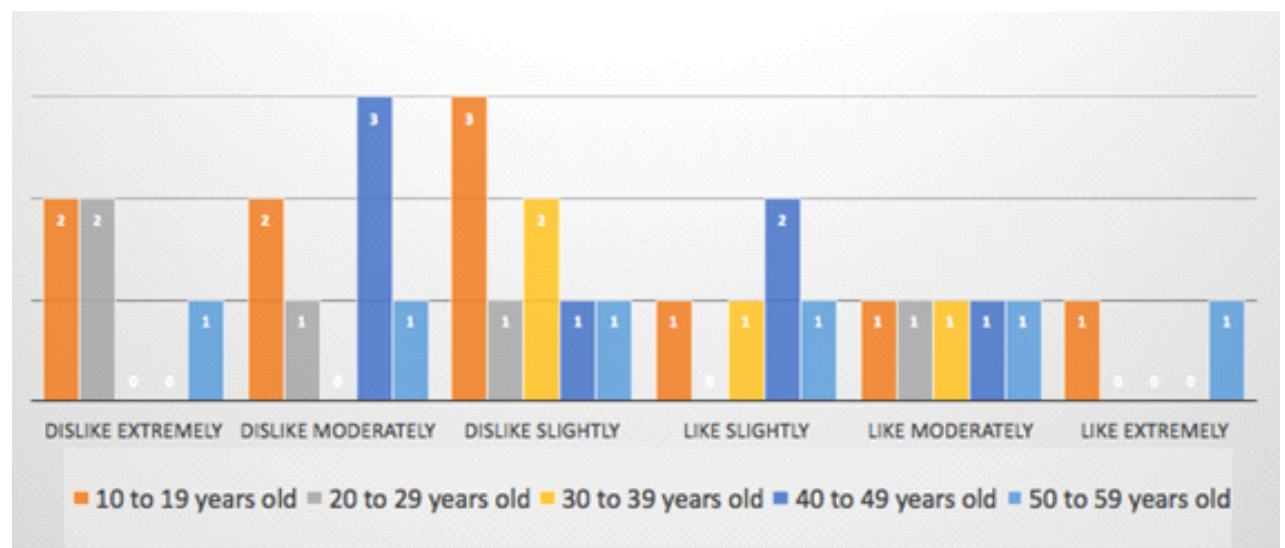

Figure 9. Combined frequency graph for brew B 


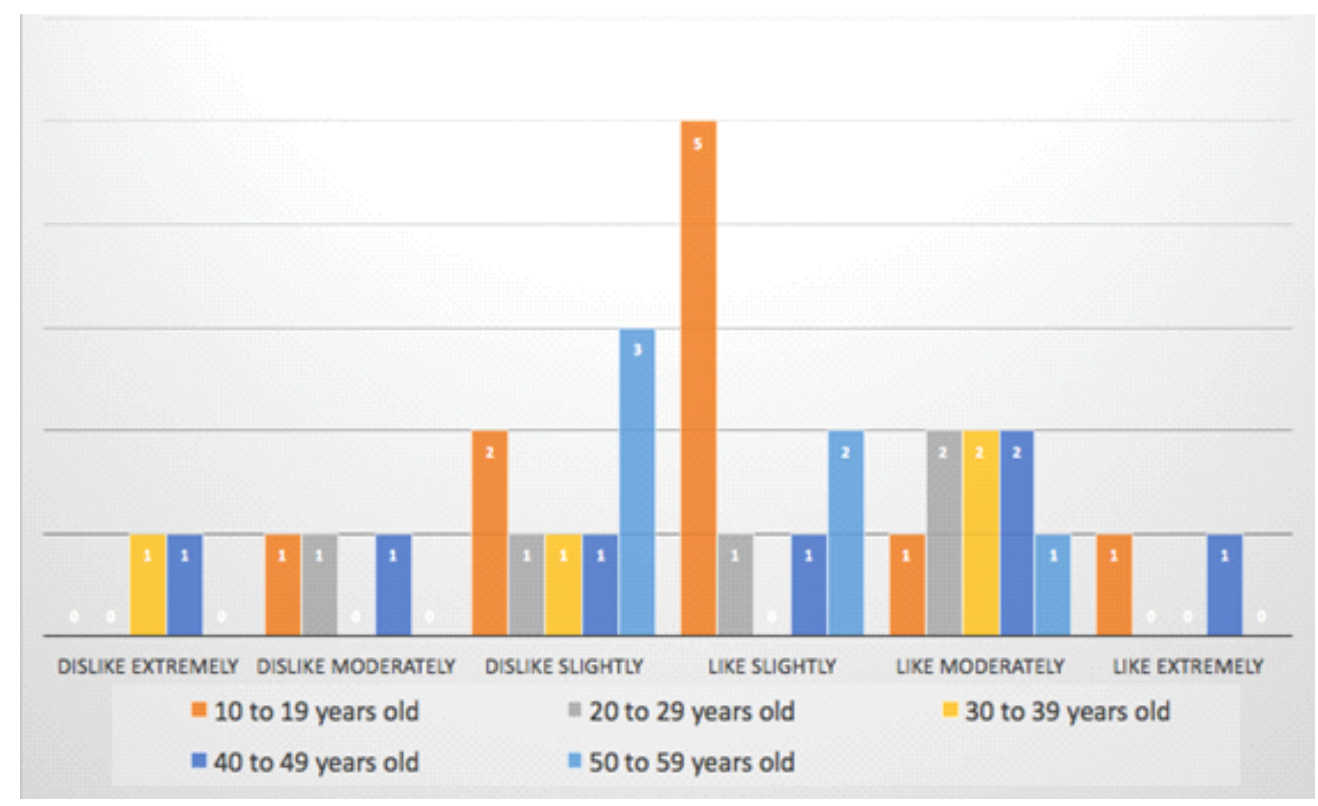

Figure 10. Combined frequency graph for brew C

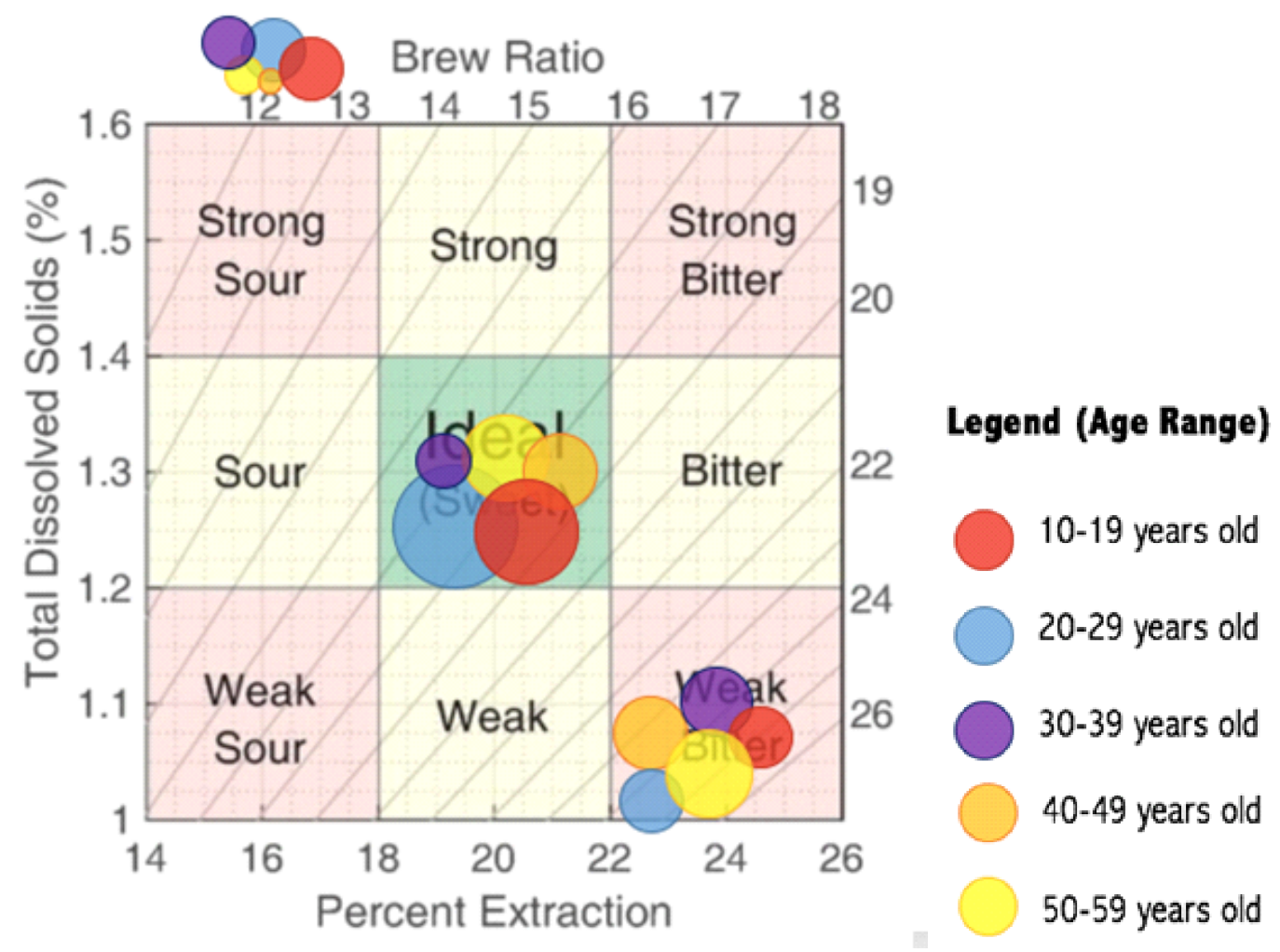

Figure 11. Data presented in the form of a bubble chart 


\section{CONCLUSIONS}

Based on the data collected from the taste tests as well as the graphs created from the data, no clear trend or relationship between age and coffee preference is evident. This, however, could be a result of the somewhat small sample size used for the taste test. If a larger group of people was given the same test, it is possible that a trend would become more clear. As for overall coffee preference, the combined data does indeed reflect the standard preferences set by the regions of the SCA brewing control chart. While these findings are also subject to change based on factors such as sample size, it can be concluded from the data collected in this study that a new brewing control chart is not currently necessary.

\section{ACKNOWLEDGEMENTS}

I would like to thank Mrs. Anne Love and Mr. Todd Gordon for assisting me in many ways throughout the research process, including preparing materials, giving suggestions for improvement, and answering questions in times of confusion. I am also grateful to the 32 individuals who participated in the taste test and provided valuable information. This research was supported by Concordia International School Shanghai.

\section{REFERENCES}

Anonim (2018)Toward a new brewing control chart for the $21^{\text {st }}$ century." ACS Publications, Journal Agricultural Food Chemistry, 6621, 5301-5309.

Fleming, A. (2013). Changing tastes: Food and Ageing. The Guardian. Guardian News and Media.

Frost, S. (2018). Demystifying, updating and expanding the Brewing Control Chart. Expo 2018 Lecture. Specialty Coffee Association News.

Ristenpart, W.D. \& T. Kuhl (2017). The Design of Coffee: an Engineering Approach. CSI Publising Platform.

SCAE (2013). European Extraction Preferences in Brewed Coffee. Specialty Coffee Association of Europe.

Suarez; M. Haft \& Harrison (2013). How to make perfect coffee. The Atlantic. Atlantic Media Company. 